\title{
CW AND Q-SWITCHED PERFORMANCE OF END-PUMPED Yb:YAG LASER WITH ELLIPTICAL MODE GEOMETRY
}

\author{
R. Antipenkov, D. Stučinskas, and A. Varanavičius \\ Department of Quantum Electronics, Vilnius University, Saulètekio 9, LT-10222 Vilnius, Lithuania \\ E-mail: darius.stucinskas@ff.vu.lt
}

Received 16 January 2009; revised 8 June 2009; accepted 18 June 2009

\begin{abstract}
We report the high beam quality diode end-pumped Q-switched Yb:YAG laser operating at $1030 \mathrm{~nm}$ wavelength with elliptical cavity mode configuration operating at $1-100 \mathrm{kHz}$ repetition rates. We have performed measurements of highly astigmatic thermal lens in laser active element by means of Shack-Hartmann wavefront sensor that provides necessary data for laser cavity design. With optimized laser cavity the output beam quality parameter $M^{2}$ does not exceed 1.2 value even at maximum pump power of $50 \mathrm{~W}$.
\end{abstract}

Keywords: Yb:YAG, elliptical mode, thermal lens

PACS: $42.55 . \mathrm{Xi}, 42.60 . \mathrm{By}$

\section{Introduction}

Yb:YAG medium was demonstrated to be a promising candidate for efficient diode pumped laser systems. The losses caused by excited-state absorption, upconversion, and concentration quenching due to simple energy level structure of $\mathrm{Yb}: \mathrm{YAG}$ are negligible [1]. Nevertheless, despite very low quantum defect in this medium the average power and beam quality of these solid state lasers are limited by the onset of thermooptic distortion and birefringence [2,3]. A variety of resonator designs and novel pumping schemes has been invented in order to minimize these effects. One of the most significant steps in achieving high average powers was the development of thin disk laser [4]. However, this design tends to be quite complex due to multiple passes of pump beam through a short active element. End-pumped schemes offer more reliable and less expensive laser designs yielding an optical to optical efficiency of more than $40 \%[5,6]$. Traditionally a rod-shaped active element was used in such set-ups. Unfortunately, this leads to depolarization losses due to thermally induced birefringence in laser active element [7]. Thin slab active element geometry is attractive due to efficient heat removal and offers more convenient distribution of thermally induced stress in active element, thus offering significant improvement of high power diode pumped solid-state laser operation [8]. However there is a limiting factor of crystal fracture due to stress, induced by non-uniform thermal expansion, as in an end-pump geometry the heat load is concentrated in a small volume while the rest of the laser crystal is cooled. The employment of elliptical mode configuration allows for a larger mode area in active element and consequently for higher output pulse energies and average power scaling, as in that case the heat load is distributed in larger volume without losing in cooling efficiency $[9,10]$. Nevertheless, this approach leads to the formation of power dependent astigmatic thermal lens which can seriously affect the resonator stability [11], therefore it requires a nontrivial laser cavity design, employing cylindrical optics and accounting for the dynamic focusing power of thermal lens.

In this contribution we report diode end-pumped Yb:YAG laser with elliptical cavity mode configuration. We present the results on numerical modelling of laser cavity based on the measurements of astigmatic thermal lens in an active element and on the laser performance in free running and Q-switched mode, featuring a high beam quality $\left(M^{2}<1.1\right)$ even at maximum laser powers.

\section{Measurement of thermal lensing}

Elliptical pump geometry leads to non-symetrical temperature distribution in laser crystal and, consequently, to astigmatic thermal lens. The data on thermally induced lens in diode pumped Yb:YAG has 


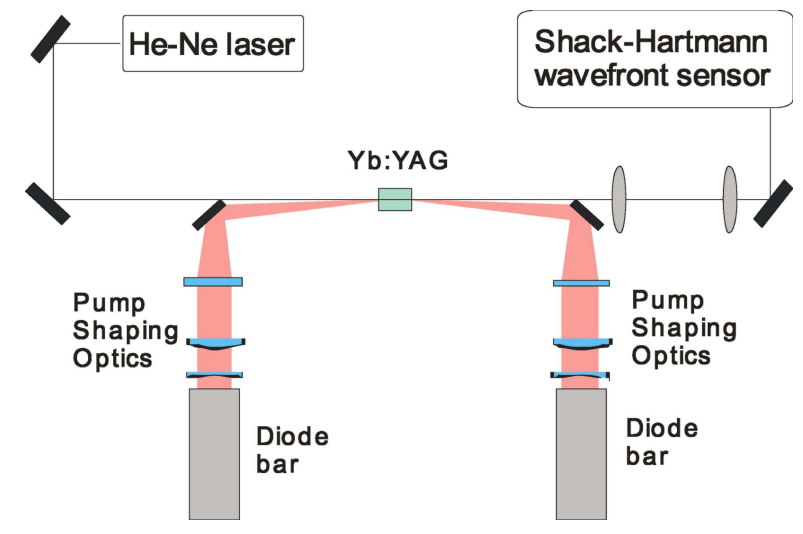

Fig. 1. Set-up for measuring the thermal lens focusing power in laser active element by means of Shack-Hartmann sensor.

been already published [12], however the measurements have been performed only for case of symmetrical pump and lasing modes with pump power not exceeding $6 \mathrm{~W}$. Therefore, in order to have more accurate data for laser design, we have performed the thermal lens measurements for elliptical pump configuration and for higher pump powers. As an active element we have used Yb:YAG crystal of 5\% doping concentration. The crystal was shaped as a thin plate $1 \mathrm{~mm}$ high, $7 \mathrm{~mm}$ wide, and $5 \mathrm{~mm}$ long. The crystal was put between two sapphire plates on a water-cooled copper heat sink. Such configuration utilizes the largest surface area for effective cooling of thin plate-shaped laser crystal and this is especially effective when the heat load is distributed in a large crystal volume [10]. In order to achieve higher pump power densities we have chosen a pump scheme where the laser active element is longitudinally pumped from both ends. We have used two high brightness polarization preserving diode laser pump modules of $40 \mathrm{~W}$ maximum optical output power at $940 \mathrm{~nm}$ wavelength. These modules are produced by Light Conversion, Ltd. and contain special assemblies of micro-optic elements that are used for the shaping of diode laser bars' radiation. The pump beam from the modules focuses to almost symmetric beam spot of $\sim 250 \mu \mathrm{m}$ in diameter and has a comparatively low divergence (beam quality parameters in different planes are $M_{\text {fast }}^{2}=12$ and $M_{\text {slow }}^{2}=27$ ). The pump beam was reshaped to elliptical one with transverse dimensions of $280 \times 1000 \mu \mathrm{m}^{2}$ in the laser crystal using a system of lenses (pump shaping optics PS). The resulting pump power from each diode laser bar after the reshaping of the beam was $26 \mathrm{~W}$ due to the losses on beam-shapers, lenses, and mirrors.

We employed a Shack-Hartmann wavefront sensor for measurement of the phase distortions acquired by probe beam of $\mathrm{He}-\mathrm{Ne}$ laser after passing the pumped

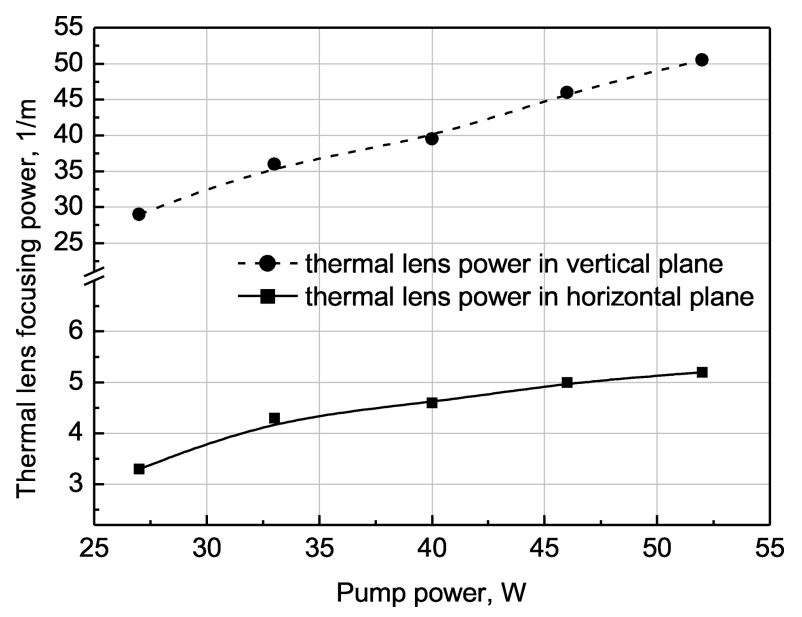

Fig. 2. Thermal lens focusing power in horizontal (width) and vertical (height) planes, depending on pump power, measured by ShackHartmann wavefront sensor. Thermal lens is highly astigmatic and its focusing power may differ up to 10 times in orthogonal planes.

laser crystal (see experimental set-up presented in Fig. 1). The Shack-Hartmann wavefront sensor was built using a $40 \times 40$ lenslet array with lenslet size of $108 \mu \mathrm{m}$ and a Dalsa 1M15 CCD camera. In order to match the dimensions of pumped region in laser crystal and lenslet array we used a magnifying 4F imaging lens system. Different values of the imaging system magnification were set for thermal lens measurements in horizontal and vertical directions, optimizing in this way the resolution of the registration system.

Variation of the thermally induced lens's focusing power, calculated from data of wavefront distortion measurements, versus total pump power is presented in Fig. 2. These results show that the thermal lens focusing power differs up to 10 times in horizontal and vertical directions at the highest pump power. Thermal lens measurements were performed in non-lasing conditions only due to technical limitations and the complexity of experimental laser resonator. However we should note that in lasing conditions the thermal lens can be up to 3 times smaller than in non-lasing conditions, as simulated emission dominates over fluorescence and non-radiative decay, thus reducing the thermal loading [12]. Therefore, the expected focal length of thermal lens in lasing conditions should be within $\sim 300-600 \mathrm{~mm}$ range in horizontal and within $\sim 30$ $60 \mathrm{~mm}$ range in vertical planes.

\section{Laser design}

\subsection{Numerical modelling}

The goal of this numerical modelling was to find out optimum laser resonator parameters at which the laser 


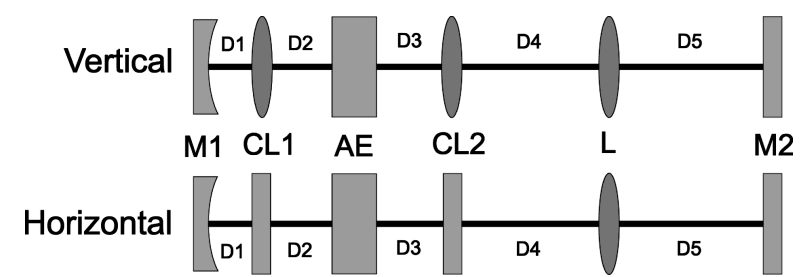

Fig. 3. Resonator model used in numerical calculations.

reaches stable operation and is least sensitive to thermal lensing. Additionally, the effects of an elliptical thermal lens on the resonators' output mode were investigated.

Figure 3 depicts the resonator model used in computer simulations. Cylindrical lenses, CL1 and CL2, were considered to be thin. The active element was replaced by a variable strength thin lens, which stands for thermal lens induced in an active element. M1 is spherical mirror with $R=1500 \mathrm{~mm}, \mathrm{M} 2$ is flat output mirror, CL1 and CL2 are cylindrical lenses of $f_{\mathrm{cl}}$ focal length, $\mathrm{AE}$ is active element, $\mathrm{L}$ is lens with $f=500 \mathrm{~mm}$.

The modelling was performed in two spatial directions: in vertical direction the curvature of cylindrical lenses CL1 and CL2 had an effect on the beam and in the horizontal direction. The thermal lens is considered to be astigmatic with its focusing power varying in the ranges corresponding to those evaluated from measurements. The resonator was modelled using an $A B C D$ matrix formalism well described in [13]. All elements in the resonator are given a corresponding $A B C D$ matrix and the path of the beam is computed after one complete roundtrip around the resonator. $A B C D$ matrices of the resonator elements are multiplied in the order in which the beam has passed through them. The parameters of interest - stability parameter $\tilde{m}$ and output beam radius $\omega$-were computed using the following relations:

$$
\tilde{m}=\frac{A+D}{2},
$$

$$
\omega^{2}=\frac{|B| \lambda}{\pi} \sqrt{\frac{1}{1-m^{2}}}
$$

where $\lambda$ is the resonator's operating wavelength, parameter $\tilde{m}$ representing the resonator stability is a half trace of all system $A B C D$ matrix and is invariant with respect to the plane of reference, and $A, B$, and $D$ are the elements of the cavity $A B C D$ matrix.

Main criterion for the resonator geometry selection was its stability within a broad range of thermal lens values, with special attention devoted to high pump power range. Another important optimization criterion is a good cavity mode overlap with the pump beam in active element that ensures a high eficiency of pump conversion to laser output. In addition we were seeking for a circular beam profile at laser output. Different sets of cylindrical lenses were used in numerical modelling in order to find an optimum performace for thermal lens values obtained from measurements. Cavity configuration was optimized with reference to criteria mentioned above, by changing position of cylindrical lenses inside resonator, without altering the overall length of cavity. In all cases, the distance between cylindrical lens and active element was slightly smaller than the focal length of cylindrical lens. Obviously, the mode parameters in horizontal direction are not sensitive to cylindrical lens's focal length and position. Main results of numerical modelling are presented in Figs. 4-6. As we can see from Fig. 4, the output beam radius in vertical direction remains nearly constant for thermal lens focal lenghts above $100 \mathrm{~mm}$. For thermal lens focal lenghts below $100 \mathrm{~mm}$ the output beam size starts to rise, until the resonator becomes unstable (see Fig. 5). In horizontal direction, the output beam diameter decreases as the thermal lens focal length drops. Numerical modelling shows that for $f_{\mathrm{cl}}=150 \mathrm{~mm}$ cylindrical lens the output

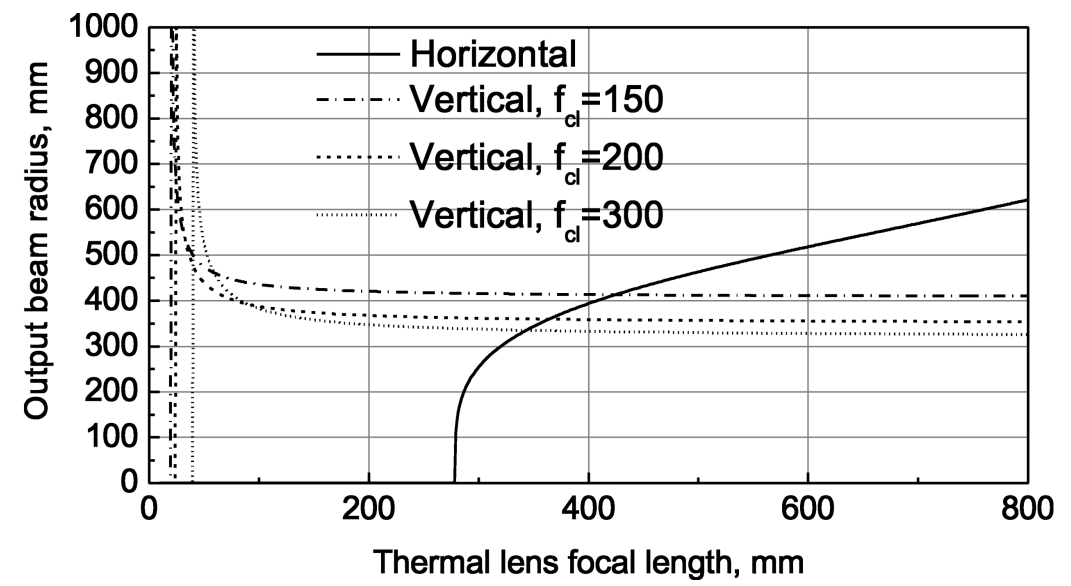

Fig. 4. Output beam radius versus thermal lens focal length at three sets of cylindrical lenses CL1 and CL2 (for horizontal and vertical directions). 


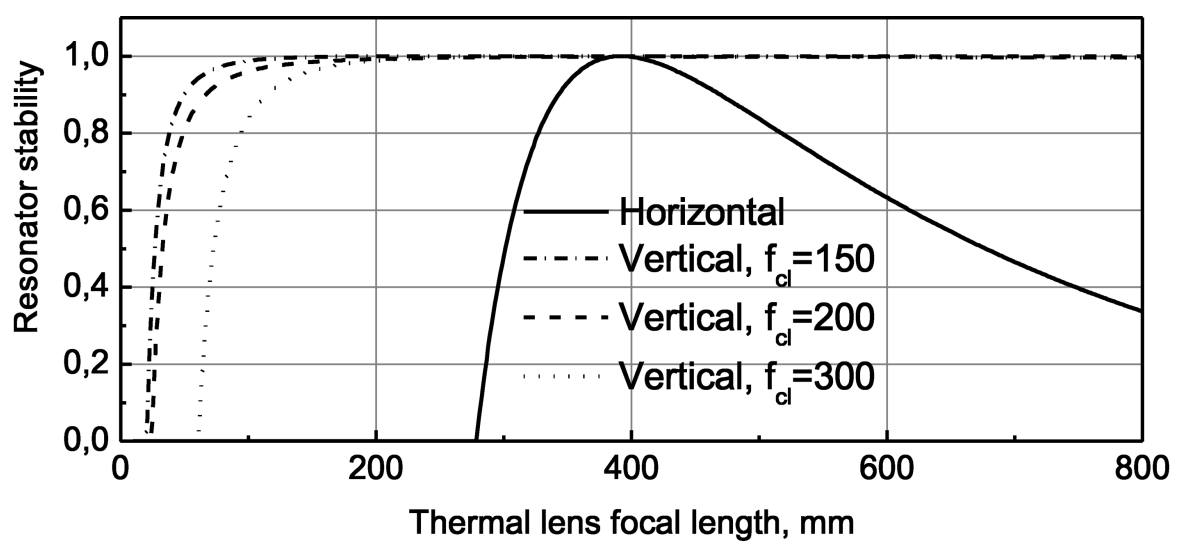

Fig. 5. Resonator stability versus thermal lens focal length at three sets of cylindrical lenses CL1 and CL2 (for horizontal and vertical directions).

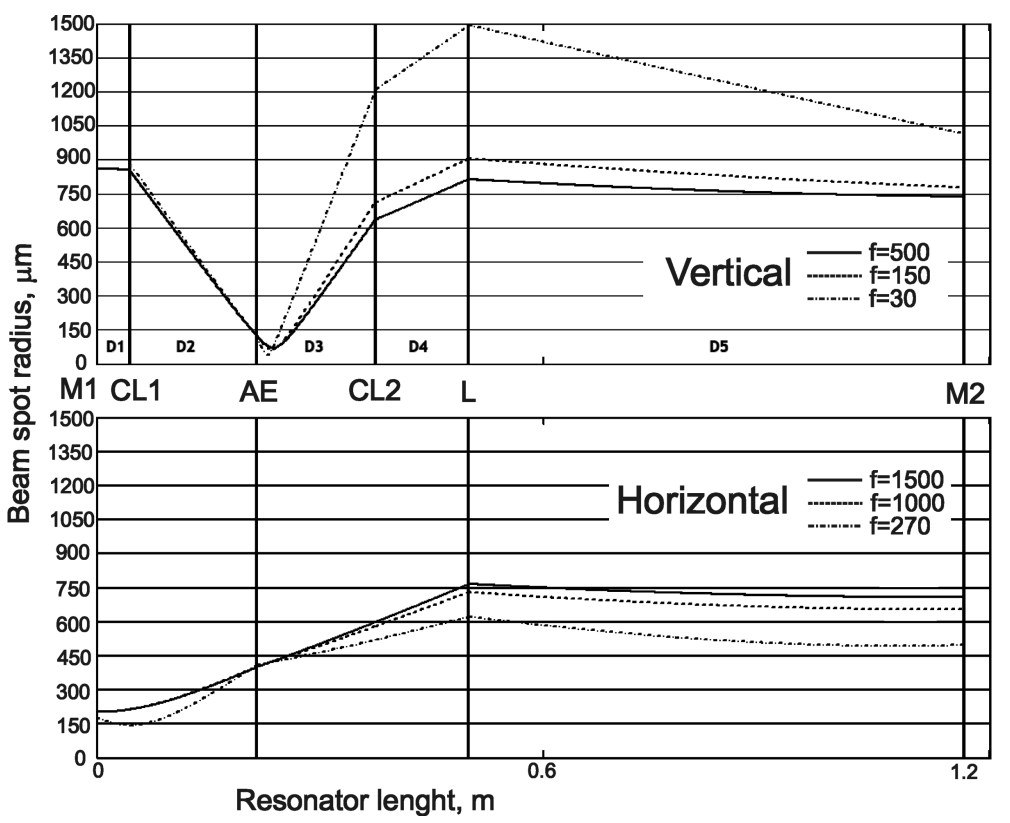

Fig. 6. Mode radius variation in laser cavity for different values of thermal lens (for $f_{\mathrm{cl}}=200 \mathrm{~mm}$ ).

beam exhibits highest elipticity ratios at thermal lens values of 300-400 $\mathrm{mm}$ in horizontal direction, and at $30-40 \mathrm{~mm}$ in vertical direction (i. e. at expected thermal lens values estimated for the highest available pump). Switching to $300 \mathrm{~mm}$ focal length cylindrical lenses would result in less elliptical output beam profile, but at a cost of reduced resonator stability range in vertical direction, limiting it to thermal lense focal length value of $60 \mathrm{~mm}$. A $200 \mathrm{~mm}$ focal length cylindrical lens ensures stable resonator for thermal lenses above $25 \mathrm{~mm}$ (in vertical direction), and has the smallest output beam radius when the thermal lens focal length is below $100 \mathrm{~mm}$ (in vertical dirrection). Mode radius variation in laser cavity for different values of thermal lens (for $f_{\mathrm{cl}}=$ $200 \mathrm{~mm}$ ) is shown in Fig. 6. One can see that the chosen geometry leads to aproximately $240 \times 800 \mu \mathrm{m}^{2}$ beam spot size which changes by no more than $10 \%$ when the available pump power is varied.

\subsection{Experimental set-up}

The outline of the resonator set-up is shown in Fig. 7. There are two identical cylindrical lenses CL introduced into the resonator to match the elliptical lasing mode and pump beam inside the laser active element. Pockels cell modulator coupled with a $\lambda / 4$ phase plate was employed for Q-switch operation mode.

In this set-up the pump was slightly non-collinear in order to avoid the optical damage of laser diode modules by counter propagating pump beams.

The actual lasing mode dimensions in Yb:YAG crystal were measured by imaging the crystal plane into a CCD camera. For this measurement a fused silica 


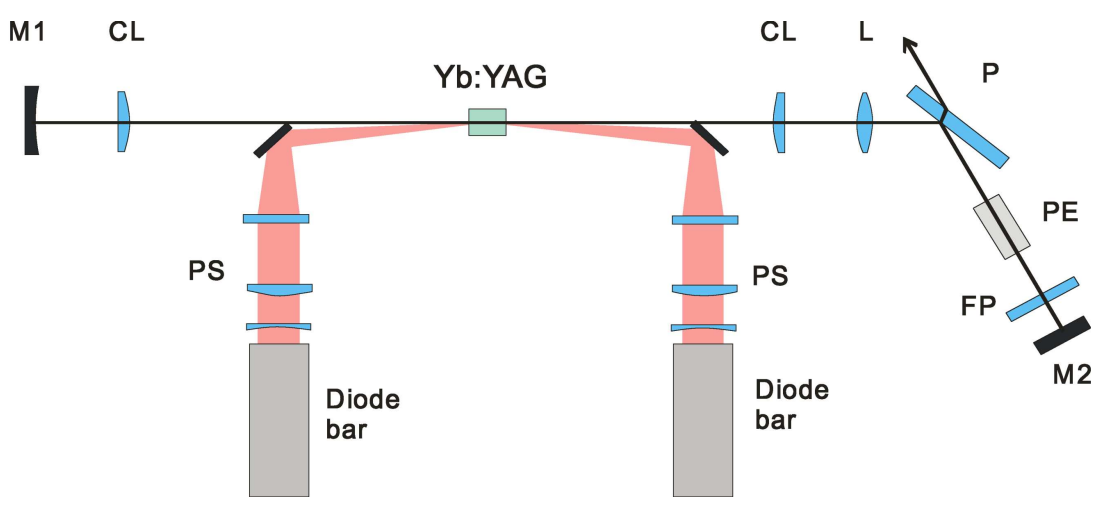

Fig. 7. Outline of the resonator with elliptical mode geometry. Pump beams from two diode laser modules were focused onto a thin Yb:YAG slab from both ends into an elliptical spot with transversal dimensions of $280 \times 1000 \mu \mathrm{m}^{2}$. M1 and M2 are cavity mirrors $\left(R_{\mathrm{M} 1}=1500 \mathrm{~mm}\right.$, M2 is a plane mirror), $\mathrm{CL}$ is cylindrical lens $\left(f_{\mathrm{cl}}=200 \mathrm{~mm}\right), \mathrm{L}$ is lens $(F=500 \mathrm{~mm}), \mathrm{P}$ is polarizer, PE is Pockels cell, FP is $\lambda / 4$ phase plate, PS is pump shaping lens system.

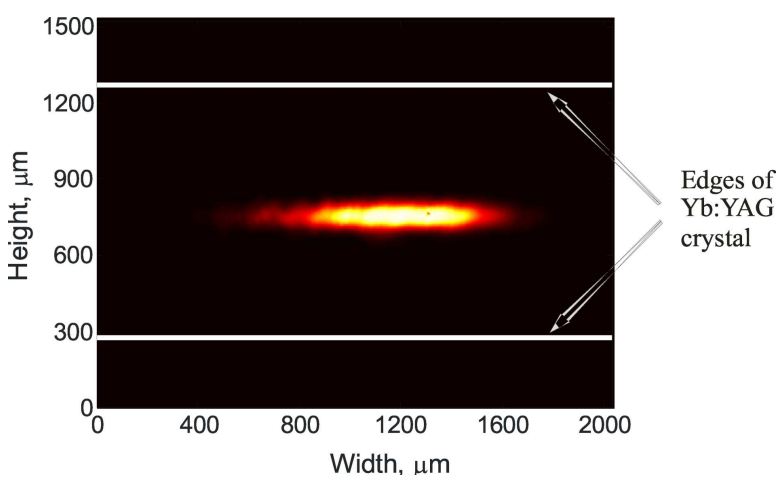

Fig. 8. Intensity distribution of laser radiation in the active element. The beam spot dimensions are $150 \times 1000 \mu \mathrm{m}^{2}$.

plate was introduced in between the Yb:YAG crystal and cylindrical lens CL and the reflection from the plate was directed through the imaging lens to CCD camera. The measured beam spot transversal dimensions were $150 \times 1000 \mu \mathrm{m}^{2}$ (see Fig. 8). The size of elliptical laser mode along a major axis was close to that of the pump spot; however, its extent along the minor axis was $\sim 40 \%$ less than the pump spot size.

\section{Laser performance in CW and Q-switched laser regimes}

As the first step the laser was tested in CW operation regime. In this case the Pockels cell modulator was switched off and the laser output through polarizer was optimized for maximum value at given pump powers by changing the rotation angle of the phase plate. Such coupling of phase plate with polarizer is equivalent to laser operation with an output mirror of variable transmittance. The dependence of average laser output power on pump is shown in Fig. 9. We have obtained a maximum laser output power of $8.3 \mathrm{~W}$ (lasing wavelength $1030 \mathrm{~nm}$ ) at $52 \mathrm{~W}$ pump power and the lasing

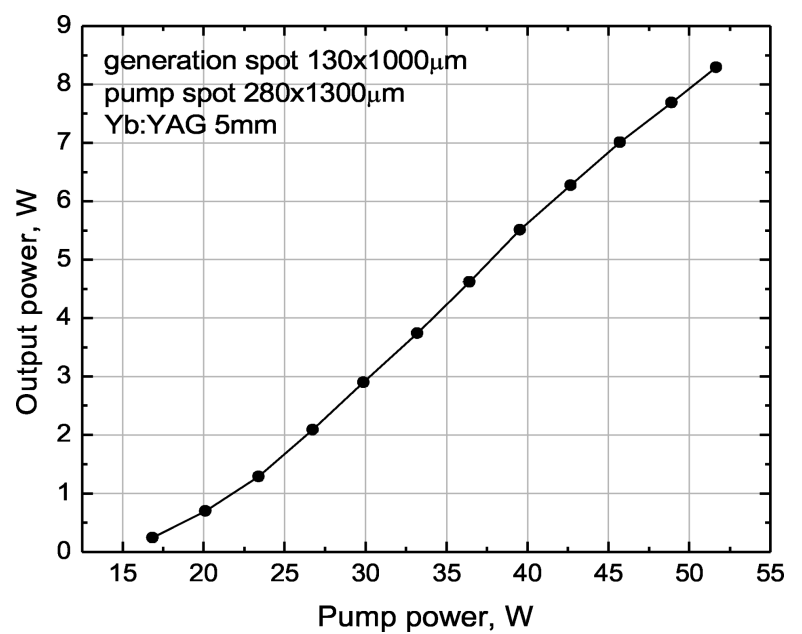

Fig. 9. Measured laser output power dependence on pump power in CW mode.

threshold was about $15 \mathrm{~W}$. These results are comparable to those presented by other groups $[8,9]$. The average slope of this curve is $24 \%$. Note the almost linear growth of the laser output with pump power indicating negligible impact of thermo-optical effect on laser operation.

We have calculated the optimum effective output coupler transmittance using the values of average power of radiation leaking through the mirror $\mathrm{M} 2$ and have found out that it steadily grows from $20-22 \%$ at threshold to the value of $38 \%$ at the maximum output power.

BBO crystal based Pockels cell of $3 \mathrm{~mm}$ clear aperture (LightGate 3 from Cleveland Crystal Inc.) and Pockels cell driver (PD4 from Bergmann Messgeräte Entwicklung KG) allowing the operation at repetition rates of up to $100 \mathrm{kHz}$ were employed for laser operation in Q-switched mode. Switching of the cavity to high-Q conditions was performed by applying $\sim 2.12 \mathrm{kV}$ pulse to Pockels cell. The moment of cavity 


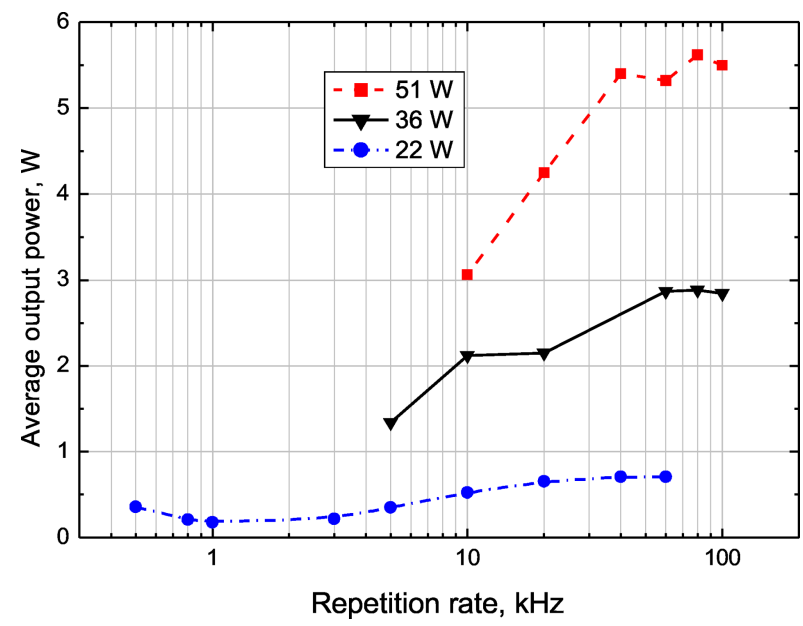

(a)

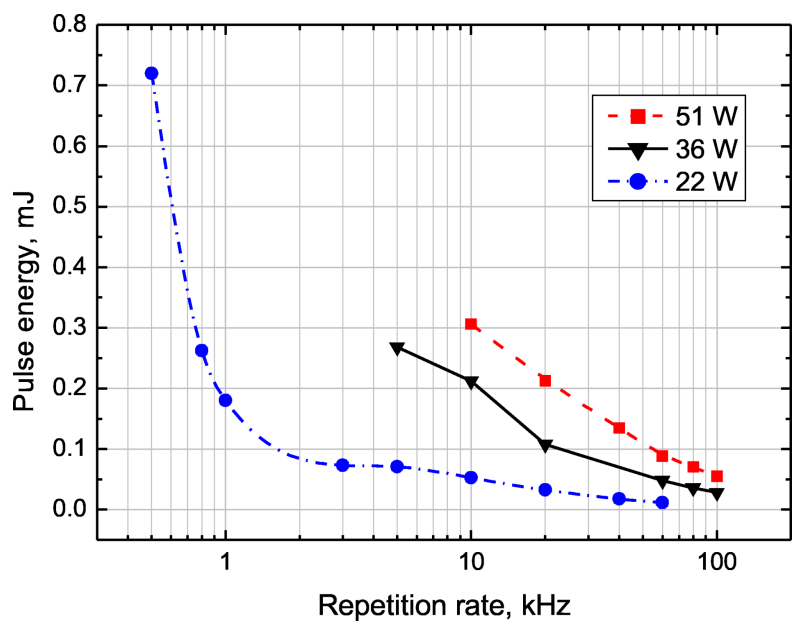

(b)

Fig. 10. Laser output in Q-switched mode operation: (a) average output power versus repetition rate at given pump powers, (b) laser pulse energy versus repetition rate at given pump powers.

dumping was regulated by the pulse width of high voltage driving pulse and during the measurements this was set to obtain the highest average output power. The laser output pulse duration in this regime was $8 \mathrm{~ns}$, which corresponds to the duration of cavity round trip. The dependences of measured average output power and corresponding energy per pulse on laser repetition rate for different values of pump power are presented in Fig. 10.

The maximum average power of $\sim 5.5 \mathrm{~W}$ was obtained at repetition rates of $30-100 \mathrm{kHz}$. We have observed a relatively fast drop of average power when decreasing the repetition rate below $30 \mathrm{kHz}$. That is caused by the appearance of irregular pulsing of laser output when the laser cavity dumping rates approach the inverse upper state lifetime of $\mathrm{Yb}: \mathrm{YAG}(\tau=0.95 \mu \mathrm{s})$ [14]. The appearance of this phenomenon is a function of the high-Q phase duration, i.e. depends on the moment of cavity dumping. In the case when cavity dumping is performed in early stage of amplification the circulating pulse cannot extract the whole stored energy form the amplifier medium and a large fraction of initial gain remains at the end of the high-Q phase. In this case the active medium gain has enough time to recover during a following low-Q phase. However, after setting the cavity dumping moment closer to the moment of amplification saturation, the energy of amplified pulse increases while the remaining gain at the end of high-Q phase decreases and the gain cannot recover the previous value during low-Q phase. As a result, the system becomes unstable and the laser output exhibits multi-energy behaviour. So, during the measurements the pulse width of high voltage driving pulse for Pockels cell was adjusted for maximum output power, but nevertheless keeping the system in the stable operation conditions. We should note that at lower pulse repetition rates the pump power was reduced in order to avoid optical damage of laser active element.

\section{Beam quality measurement}

Beam intensity profile was measured by CCD camera at $\sim 4 \mathrm{~m}$ distance from the laser output. As seen in Fig. 11, the output beam profile remains close to Gaussian one even at highest output powers, however when the pump power increases the symmetrical output beam becomes elliptical. According to numerical modelling (see Fig. 4) the output beam dimension in horizontal plane decreases as the thermal lens value increases. This leads to higher divergence in horizontal direction.

We use a method described in ISO 11146 standard to measure the laser beam quality parameter $M^{2}$. The
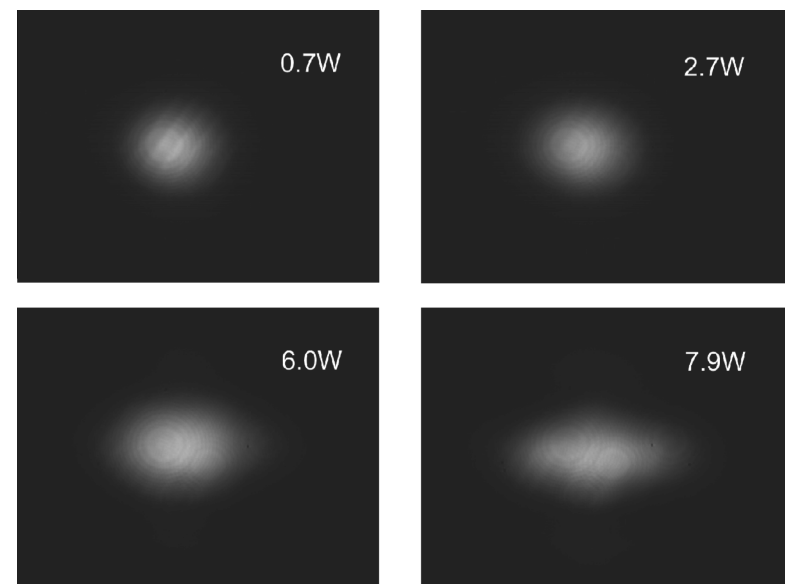

Fig. 11. Beam intensity profile taken by a CCD camera at $\sim 4 \mathrm{~m}$ distance from the laser output. 


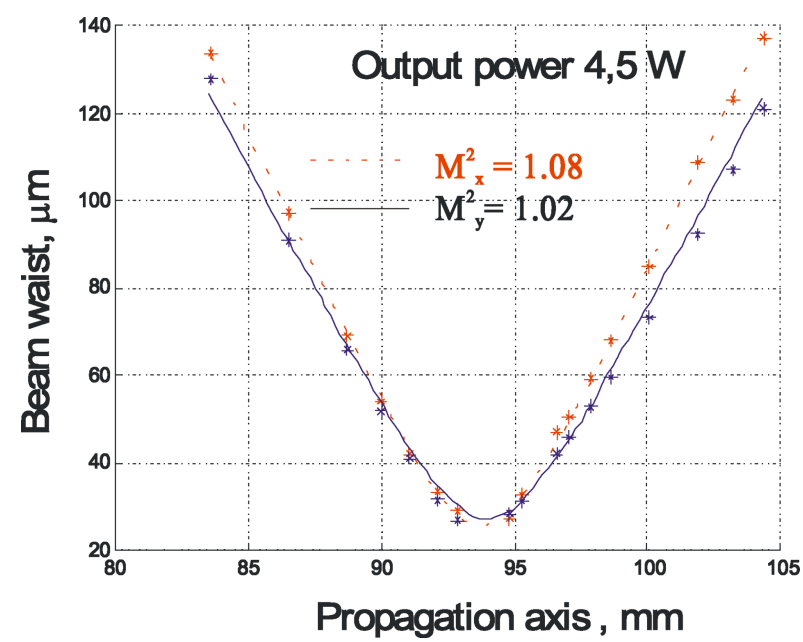

(a)

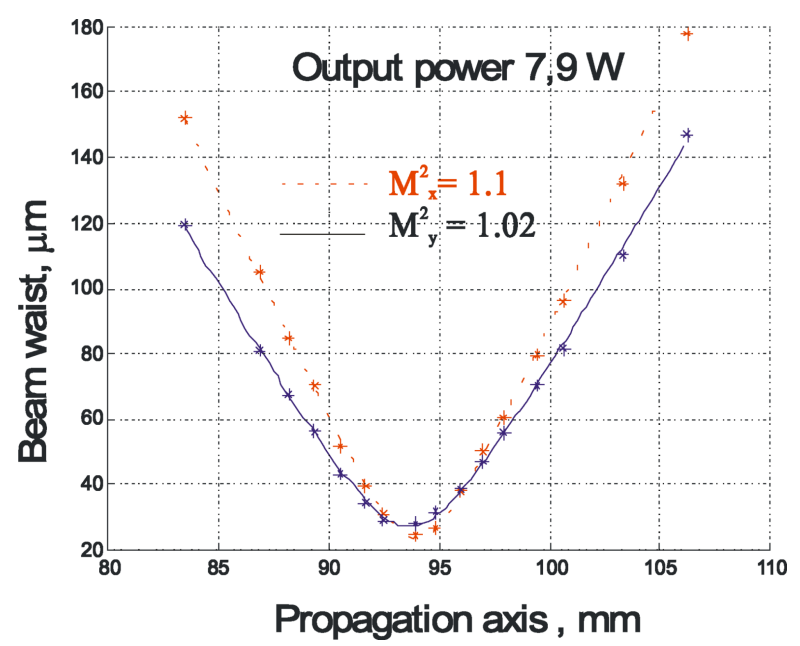

(b)

Fig. 12. Laser output beam $M^{2}$ parameter measurement at 36 and $48 \mathrm{~W}$ pump power. Solid line corresponds to vertical beam section, dotted line to horizontal.

beam is focused by a lens and then a number of beam spot measurements are made by a CCD camera along the beam propagation direction. In our case we kept the lens position fixed and the CCD camera was being moved to measurement positions. After determining the beam width in every position a comparison with Gaussian beam propagation was made in order to estimate the $M^{2}$ parameter of the laser beam.

As we can see in Fig. 12, the beam quality measurement resulted in $M^{2}$ values close to unity. The beam quality in horizontal direction is slightly decreased, whereas in vertical direction the beam quality remains very good. This probably occurs due to high ellipticity of the beam in laser active element, meaning that the beam is more sensitive to thermal lens and its aberrations along the direction of larger beam dimension. We can also see that the laser beam is slightly astigmatic, as there is a focus shift between horizontal and vertical directions. However, the beam quality is excellent even at higher powers and the astigmatism can be easily compensated by employing simple cylindrical optics.

\section{Conclusions}

In this work the operation of diode end-pumped Yb:YAG laser with elliptical mode geometry was investigated in $\mathrm{CW}$ and Q-switch regimes. In Q-switch mode the laser produced $8 \mathrm{~ns}$ pulses with average output power up to $5.5 \mathrm{~W}$ at pump power of $52 \mathrm{~W}$, while in $\mathrm{CW}$ operation mode the $8 \mathrm{~W}$ output power was achieved. We have measured the focusing power of astigmatic thermal lens in laser active element and examined the quality of output beam at different output power. In spite of strongly astigmatic thermal lens due to optimized cavity design the output beam exhibits high spatial quality. Slight rise of laser output beam ellipticity reaching the ratio of 1.2 for the highest pump power was observed. Nevertheless, the beam quality parameter $M^{2}$ in both vertical and horizontal plane is close to unity, thus the output beam can be easily reconstructed to the circular mode by a cylindrical telescope. We believe that such laser design offers good prospects for power scaling of diode pumped lasers.

\section{References}

[1] Chen Li, Qiang Liu, Mali Gong, Gang Chen, and Ping Yan, Q-switched operation of end-pumped Yb:YAG lasers with non-uniform temperature distribution, Opt. Commun. 231, 331-341 (2003).

[2] D.J. Ripin, J.R. Ochoa, R.L. Aggarval, and T.Y. Fan, 300-W cryogenically cooled Yb:YAG laser, IEEE J. Quantum Electron. 41, 1274-1277 (2005).

[3] D.C. Brown, Nonlinear thermal and stress effects and scaling behavior of YAG slab amplifiers, IEEE J. Quantum Electron. 34, 2393-2402 (1998).

[4] A. Giesen and J. Speiser, Fifteen years of work on thindisk lasers: Results and scaling laws, IEEE J. Select. Topics Quantum Electron. 13, 598-609 (2007).

[5] J.H. Hellström, S. Bjurshagen, V. Pasiskevicius, J. Liu, V. Petrov, and U. Griebner, Efficient Yb:KGW lasers end-pumped by high power diode bars, Appl. Phys. B 83, 235-239 (2006).

[6] F. Hoos, S. Li, T.P. Meyrath, B. Braun, and H. Giessen, Thermal lensing in an end-pumped Yb:KGW slab laser with high power single emitter diodes, Opt. Express 16, 6041-6049 (2008).

[7] W. Koechner, Solid-state Laser Engineering, 6th ed. (Springer, 2006). 
[8] J.M. Eggleston, T. Kane,, K. Kuhn, J. Unternahrer, and R. Byer, The slab geometry laser-Part I: Theory, IEEE J. Quantum Electron. 20, 289-301 (1984).

[9] J. Aus de Au, S.F. Schaer, R. Paschotta, C. Hönninger, U. Keller, and M. Moser, High-power diode-pumped passively mode-locked Yb:YAG lasers, Opt. Lett. 24, 1281-1283 (1999).

[10] R. Paschotta, J. Aus der Au, G.J. Spühler, F. Morier-Genoud, R. Hövel, M. Moser, S. Erhard, M. Karszewski, A. Giesen, and U. Keller, Diode-pumped passively mode-locked lasers with high average power, J. Appl. Phys. B 70, S25-S31 (2000).

[11] R. Paschotta, J. Aus der Au, and U. Keller, Thermal effects in high-power end-pumped lasers with elliptical- mode geometry, IEEE J. Select. Topics Quantum Electron. 6, 636-642 (2000).

[12] S. Chénais, F. Balembois, F. Druon, G. Lucas-Leclin, and P. Georges, Thermal lensing in diode-pumped ytterbium lasers-Part II: Evaluation of quantum efficiencies and thermo-optic coefficients, IEEE J. Quantum Eletron. 40, 1235-1243 (2004).

[13] A.E. Siegman, Lasers (University Science Books, 1986).

[14] J. Dörring, A. Killi, U. Morgner, A. Lang, M. Lederer, and D. Kopf, Period doubling and deterministic chaos in continuously pumped regenerative amplifiers, Opt. Express, 12, 1759-1768 (2004).

\title{
NUOLATINĖS IR IMPULSINĖS VEIKOS IŠILGINIO KAUPINIMO Yb:YAG LAZERIS SU ELIPTINE REZONATORIAUS MODA
}

\author{
R. Antipenkov, D. Stučinskas, A. Varanavičius \\ Vilniaus universitetas, Vilnius, Lietuva
}

\begin{abstract}
Santrauka
Išnagrinèta išilginio diodinio kaupinimo Yb:YAG lazerio su eliptine moda veika. Kaupinant plokštelès formos aktyvuji elementą eliptiniu pluoštu, susidaro stipriai astigmatinis termolęšis. Atlikti termolęšio matavimai Shack'o ir Hartmann'o bangos fronto matuokliu; gauti rezultatai panaudoti matematiškai modeliuojant
\end{abstract}

lazerio rezonatorių. Surinkto eksperimentinio lazerio išèjimo galia nuolatinès veikos režime siekia $8 \mathrm{~W}$ (esant $52 \mathrm{~W}$ kaupinimo galiai). Moduliuotos kokybės režime lazeris generuoja 8 ns trukmès impulsus, o vidutinè galia siekia $5 \mathrm{~W}$. Lazerio pluošto kokybès parametras $M^{2}$ neviršija 1,2 net esant maksimaliai kaupinimo galiai. 